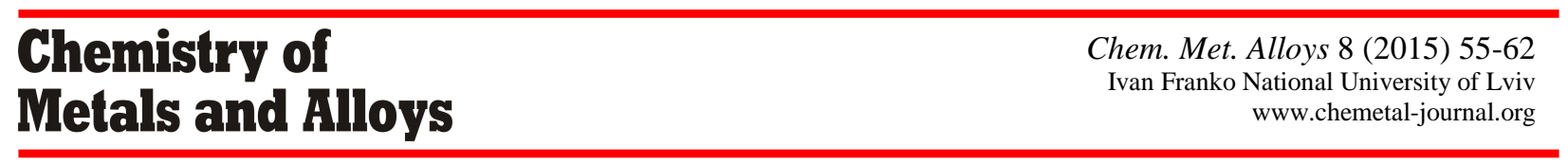

\title{
The new monoclinic structure type $\mathrm{Gd}_{4} \mathrm{ReGe}_{8}$
}

\author{
Vitaliia MYKHALICHKO ${ }^{1}$, Roksolana KOZAK $^{2}$, Roman GLADYSHEVSKII $^{1}$ \\ ${ }^{1}$ Department of Inorganic Chemistry, Ivan Franko National University of Lviv, \\ Kyryla i Mefodiya St. 6, UA-79005 Lviv, Ukraine \\ ${ }^{2}$ Laboratory of Crystallography, Department of Materials, ETH Zurich, \\ Vladimir-Prelog-Weg 5, CH-8093 Zurich, Switzerland \\ * Corresponding author.Tel: +380-32-2600388, e-mail: vitaliia.fedyna@gmail.com
}

Received May 27, 2015; accepted June 24, 2015; available on-line September 1, 2015

A new monoclinic structure type of intermetallic compounds, $\mathrm{Gd}_{4} \operatorname{ReGe}_{8}\left(m P 64-12, P 2_{1} / c, a=5.8106(7)\right.$, $\left.b=16.060(2), c=12.852(2) \AA, \beta=115.379(9)^{\circ}, R=0.0405, R_{w}=0.0866\right)$, was identified on the basis of X-ray single-crystal diffraction data. The structure of $\mathrm{Gd}_{4} \mathrm{ReGe}_{8}$ is a monoclinic derivative of the CeNiSi $\mathbf{C}_{2}$ type, formed as a result of partial ordering of $d$-element vacancies. The structure, which contains four partly occupied Re sites, is closely related to the $\mathrm{Tb}_{4} \mathrm{FeGe}_{8}$ type, where only two partly occupied Fe sites were refined.

\section{Gadolinium / Rhenium / Germanium / Bärnighausen formalism / X-ray diffraction}

\section{Introduction}

The structure type $\mathrm{CeNiSi}_{2}$ [1] is a common type of intermetallic compounds. The major part of the compounds (90) form in systems $R-T-\mathrm{Ge}$, where $R=4$-element, $T=d$-element [2]. Several superstructures of the $\mathrm{CeNiSi}_{2}$ type are also known in these systems, such as: $\mathrm{LuMnGe}_{2}$ [3], $\mathrm{YIrGe}_{2}$ [4], $\mathrm{Ce}_{2} \mathrm{Rh}_{1.35} \mathrm{Ge}_{4.65}$ [5], $\mathrm{Tb}_{4} \mathrm{FeGe}_{8}$ [6], etc. There exist also information about compounds isotypic with the structure types $\mathrm{ZrSi}_{2}$ [7] and $\mathrm{ErGe}_{2.16}$ [8], which are defect, binary variants of the structure type $\mathrm{CeNiSi}_{2}$. Compounds with $\mathrm{CeNiSi}_{2}$-type structures are known in the systems $R-\{\mathrm{Cr}, \mathrm{Ru}, \mathrm{Co}, \mathrm{Cu}\}-\mathrm{Ge}$, whereas the ternary germanides of osmium belong to the structure types $\mathrm{ZrCrSi}_{2}$ [9] and $\mathrm{YIrGe}_{2}$ [4]. Many ternary compounds in the systems $R-\{\mathrm{Mn}, \mathrm{Re}, \mathrm{Fe}, \mathrm{Rh}, \mathrm{Ir}, \mathrm{Ni}$, $\mathrm{Pd}, \mathrm{Pt}\}-\mathrm{Ge}$ adopt the $\mathrm{CeNiSi}_{2}$ type, or one of its superstructure. On the contrary, compounds with $\mathrm{CeNiSi}_{2}$-type structures, or superstructures of it, have not been observed in $R-T-\mathrm{Ge}$ systems where $T=\mathrm{Ti}, \mathrm{Zr}, \mathrm{Hf}, \mathrm{V}, \mathrm{Nb}, \mathrm{Ta}, \mathrm{Mo}, \mathrm{W}, \mathrm{Ag}, \mathrm{Au}, \mathrm{Zn}, \mathrm{Cd}$, or $\mathrm{Hg}$.

The overwhelming majority of the compounds that crystallize in the $\mathrm{CeNiSi}_{2}$ type is characterized by defects on the position of the $T$-element. For a particular $T$-element, the amount of vacancies decreases with increasing periodic number of the $R$-element. This is due to the size factor, whereas differences in deficiency within the series of compounds with the same rare-earth element and different $d$-elements, may be attributed to electronic factors (e.g. number of valence electrons).

The synthesis and structural investigation of a new compound forming in the system $\mathrm{Gd}-\mathrm{Re}-\mathrm{Ge}$ were the aim of this paper.

\section{Experimental details}

Alloys were synthesized from high-purity elements ( $\geq 99.7$ wt.\%) by arc melting on a water-cooled copper bottom under a purified (using $\mathrm{Ti}$ as a getter) argon atmosphere with a tungsten electrode. The alloys were placed into an alumina crucible and inserted into a Ta ampoule, which was then sealed by welding under $\mathrm{Ar}$ atmosphere. The samples were heated to $1350^{\circ} \mathrm{C}$ in a vacuum tube furnace at the speed of $200^{\circ} \mathrm{C} / \mathrm{h}$, kept at constant temperature for $5 \mathrm{~h}$ and then cooled down to room temperature at a cooling rate of $50^{\circ} \mathrm{C} / \mathrm{h}$. The weight losses during the preparation of the samples were about $1 \%$ of the total mass, which was $1 \mathrm{~g}$ for each alloy.

A single crystal was extracted from one of the alloys. It was mounted on a glass fiber and X-ray diffraction data were collected at room temperature on

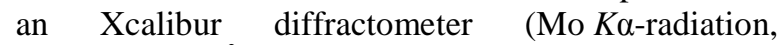
$\lambda=0.71073 \AA$, CCD detector). The structure of $\mathrm{Gd}_{4} \mathrm{ReGe}_{8}$ was solved by direct methods in the space group $P 2_{1} / c$ with the SHELXS-97 program $[10,11]$. The thermal oscillations of the atoms were described by anisotropic displacement parameters. 
Table 1 Experimental details and crystallographic data for the compound $\mathrm{Gd}_{4} \operatorname{ReGe}_{8}$.

\begin{tabular}{|c|c|}
\hline \multirow{3}{*}{$\begin{array}{l}\text { Empirical formula } \\
\text { Chemical formula weight } \\
M, \mathrm{~g} \cdot \mathrm{mol}^{-1} \\
\text { Pearson symbol, } Z\end{array}$} & $\mathrm{Gd}_{4} \mathrm{Re}_{0.991(8)} \mathrm{Ge}_{8}$ \\
\hline & 1395.92 \\
\hline & $m P 64-12,4$ \\
\hline \multirow{2}{*}{$\begin{array}{l}\text { Crystal system, space group } \\
\text { Unit-cell parameters: } a, \AA\end{array}$} & monoclinic, $P 2_{1} / c$ \\
\hline & $5.8106(7)$ \\
\hline \multirow{3}{*}{$\begin{array}{l}b, \AA \\
c, \AA \\
\beta,^{\circ}\end{array}$} & $16.060(2)$ \\
\hline & $12.852(2)$ \\
\hline & $115.379(9)$ \\
\hline Unit-cell volume $V, \AA^{3}$ & $1083.6(3)$ \\
\hline Density $D_{\mathrm{X}}, \mathrm{g} \cdot \mathrm{cm}^{-3}$ & 8.556 \\
\hline$F(000)$ & 2348 \\
\hline Diffractometer & Xcalibur Onyx \\
\hline Radiation, monochromator & Mo $K \alpha$, graphite \\
\hline Absorption correction & analytical \\
\hline Absorption coefficient & 56.972 \\
\hline Extinction coefficient & $\begin{array}{c}0.00028(2) \\
w=1 /\left[\sigma^{2}\left(F_{\mathrm{o}}{ }^{2}\right)+(0.019 P)^{2}+\right.\end{array}$ \\
\hline Weighing scheme & $\begin{array}{c}\text { 57.85P], where } \\
P=\left(F_{\mathrm{o}}^{2}+2 F_{\mathrm{c}}^{2}\right) / 3\end{array}$ \\
\hline Limiting indices & $\begin{array}{c}-5 \leq h \leq 5,-20 \leq k \leq 20 \\
-16 \leq l \leq 16\end{array}$ \\
\hline$\theta_{\min }-\theta_{\max }, \circ$ & $4.6-26.3$ \\
\hline $\begin{array}{l}\text { Number of reflections: } \\
\text { measured / unique / } \\
\text { with } F>2 \sigma(F)\end{array}$ & $\begin{array}{c}20089 / 2021 / \\
1887\end{array}$ \\
\hline \multirow{2}{*}{$\begin{array}{l}\text { Size of the crystal, mm } \\
\text { Color of the crystal }\end{array}$} & $0.09 \times 0.04 \times 0.04$ \\
\hline & gray \\
\hline $\begin{array}{l}\text { Number of refined } \\
\text { parameters }\end{array}$ & 131 \\
\hline \multirow[t]{3}{*}{ Reliability factors: } & 0.0405 \\
\hline & 0.0866 \\
\hline & 1.173 \\
\hline
\end{tabular}

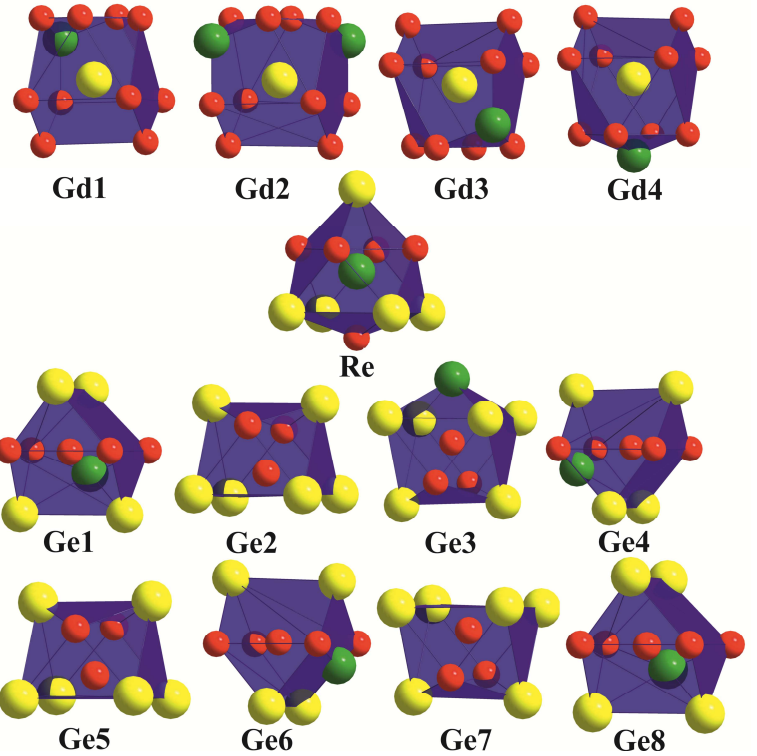

Fig. 1 Coordination polyhedra of the atoms in the structure of $\mathrm{Gd}_{4} \mathrm{ReGe}_{8}$. The sites with $<5 \%$ occupation are ignored.

Because of the partial occupancies of the Re sites, the displacement parameters were constrained to be equal. Full-matrix least-squares refinements of the positional and anisotropic displacement parameters were performed on $F^{2}$ using the SHELXL-97 program.

Details of the data collection and structure refinement for $\mathrm{Gd}_{4} \mathrm{ReGe}_{8}$ are given in Table 1. The coordinates and equivalent displacement parameters of the atoms in the structure of $\mathrm{Gd}_{4} \mathrm{ReGe}_{8}$ are listed in Table 2, and the anisotropic displacement parameters in Table 3. The coordination polyhedra are shown on Fig. 1.

Table 2 Atomic coordinates, equivalent displacement parameters and site occupancies for $\mathrm{Gd}_{4} \mathrm{ReGe}_{8}$, space group $P 2{ }_{1} / c$.

\begin{tabular}{c|c|l|l|l|c|c}
\hline Atom & Wyckoff position & \multicolumn{1}{|c|}{$x$} & \multicolumn{1}{c|}{$y$} & \multicolumn{1}{c|}{ Occ. } & $U_{\mathrm{eq}}, \AA^{2}$ \\
\hline Gd1 & $4 e$ & $0.05953(13)$ & $0.10009(4)$ & $0.43430(6)$ & 1 & $0.0096(2)$ \\
Gd2 & $4 e$ & $0.31290(13)$ & $0.10298(4)$ & $0.18816(6)$ & 1 & $0.0107(2)$ \\
Gd3 & $4 e$ & $0.56641(13)$ & $0.39883(4)$ & $0.44145(6)$ & 1 & $0.0098(2)$ \\
Gd4 & $4 e$ & $0.81161(13)$ & $0.39195(4)$ & $0.18627(6)$ & 1 & $0.0112(2)$ \\
Re1 & $4 e$ & $0.066(13)$ & $0.293(4)$ & $0.428(5)$ & $0.008(2)$ & \\
Re2 & $4 e$ & $0.18611(11)$ & $0.69791(3)$ & $0.31155(5)$ & $0.916(4)$ & $0.0098(2)$ \\
Re3 & $4 e$ & $0.318(3)$ & $0.3044(10)$ & $0.1857(14)$ & $0.0322(16)$ & \\
Re4 & $4 e$ & $0.562(3)$ & $0.2008(9)$ & $0.4335(13)$ & $0.0345(16)$ & 1 \\
Ge1 & $4 e$ & $0.0434(3)$ & $0.74867(9)$ & $0.45261(13)$ & 1 & $0.0144(4)$ \\
Ge2 & $4 e$ & $0.0634(3)$ & $0.44663(9)$ & $0.43841(12)$ & 1 & $0.0123(3)$ \\
Ge3 & $4 e$ & $0.1855(3)$ & $0.54385(9)$ & $0.31188(12)$ & 1 & $0.0109(3)$ \\
Ge4 & $4 e$ & $0.2299(3)$ & $0.25174(9)$ & $0.32864(13)$ & 1 & $0.0148(4)$ \\
Ge5 & $4 e$ & $0.3139(3)$ & $0.44346(9)$ & $0.18579(12)$ & 1 & $0.0125(3)$ \\
Ge6 & $4 e$ & $0.3968(3)$ & $0.25208(9)$ & $0.04870(13)$ & 1 & $0.0143(4)$ \\
Ge7 & $4 e$ & $0.4393(3)$ & $0.54946(9)$ & $0.06523(12)$ & 1 & $0.0122(3)$ \\
Ge8 & $4 e$ & $0.6734(3)$ & $0.24886(9)$ & $0.33061(13)$ & 1 & $0.0155(4)$ \\
\hline
\end{tabular}


Table 3 Anisotropic displacement parameters $\left(\AA^{2}\right)$ for $\mathrm{Gd}_{4} \mathrm{ReGe}_{8}$.

\begin{tabular}{c|c|c|c|c|c|c}
\hline Atom & $U_{11}$ & $U_{22}$ & $U_{33}$ & $U_{23}$ & $U_{13}$ & $U_{12}$ \\
\hline $\mathrm{Gd} 1$ & $0.0089(4)$ & $0.0099(3)$ & $0.0103(4)$ & $-0.0018(2)$ & $0.0045(3)$ & $-0.0013(2)$ \\
$\mathrm{Gd} 2$ & $0.0105(4)$ & $0.0112(3)$ & $0.0106(4)$ & $-0.0018(2)$ & $0.0046(3)$ & $-0.0010(3)$ \\
$\mathrm{Gd} 3$ & $0.0088(4)$ & $0.0100(3)$ & $0.0109(4)$ & $0.0014(2)$ & $0.0046(3)$ & $0.0016(2)$ \\
$\mathrm{Gd} 4$ & $0.0109(4)$ & $0.0112(3)$ & $0.0116(4)$ & $0.0009(2)$ & $0.0049(3)$ & $0.0008(3)$ \\
$\mathrm{Re} 1-\mathrm{Re} 4$ & $0.0084(4)$ & $0.0101(3)$ & $0.0109(3)$ & $0.0006(2)$ & $0.0043(2)$ & $0.0004(2)$ \\
$\mathrm{Ge} 1$ & $0.0123(8)$ & $0.0134(7)$ & $0.0172(8)$ & $-0.0018(6)$ & $0.0061(6)$ & $0.0010(6)$ \\
$\mathrm{Ge} 2$ & $0.0094(8)$ & $0.0161(7)$ & $0.0121(7)$ & $-0.0006(6)$ & $0.0052(6)$ & $0.0027(6)$ \\
$\mathrm{Ge} 3$ & $0.0106(7)$ & $0.0129(7)$ & $0.0101(7)$ & $-0.0002(5)$ & $0.0055(6)$ & $0.0021(6)$ \\
$\mathrm{Ge} 4$ & $0.0166(9)$ & $0.0151(7)$ & $0.0144(8)$ & $-0.0016(6)$ & $0.0084(6)$ & $-0.0037(6)$ \\
$\mathrm{Ge} 5$ & $0.0090(8)$ & $0.0193(7)$ & $0.0099(7)$ & $-0.0019(6)$ & $0.0048(6)$ & $0.0026(6)$ \\
$\mathrm{Ge} 6$ & $0.0150(8)$ & $0.0133(7)$ & $0.0158(8)$ & $0.0004(6)$ & $0.0077(6)$ & $0.0011(6)$ \\
$\mathrm{Ge} 7$ & $0.0104(8)$ & $0.0158(7)$ & $0.0114(7)$ & $-0.0017(6)$ & $0.0054(6)$ & $0.0024(6)$ \\
$\mathrm{Ge} 8$ & $0.0128(8)$ & $0.0150(7)$ & $0.0155(8)$ & $-0.0018(6)$ & $0.0030(6)$ & $0.0014(6)$ \\
\hline
\end{tabular}

\section{Results and discussion}

Investigations of compounds forming in the systems $R-\mathrm{Re}-\mathrm{Ge}$ can be found in [12-15]. Three compounds with the $\mathrm{CeNiSi}_{2}$-type structures have been reported in these systems: $\mathrm{GdRe}_{0.24-0.25} \mathrm{Ge}_{2}, \quad \mathrm{HoRe}_{0.25} \mathrm{Ge}_{2}$, and $\mathrm{LuRe}_{0.12} \mathrm{Ge}_{2}$. During a systematic investigation of the $\{\mathrm{Gd}, \mathrm{Er}\}-\mathrm{Re}-\mathrm{Ge}$ systems we found a new compound with Er and confirmed the existence of the phase with $\mathrm{Gd}$, as well in as-cast alloys as in samples annealed at $800^{\circ} \mathrm{C}$ [13]. No single crystals could be isolated and the structures were refined by the powder method. After a slightly modified synthesis (slow heating and cooling), a crystal suitable for X-ray single crystal diffraction was found. Examining the structure of the Gd-compound, we found a new monoclinic derivative of the $\mathrm{CeNiSi}_{2}$ type.

The crystal structure of the $\mathrm{CeNiSi}_{2}$ type contains layers of square antiprisms (fragments of $\mathrm{BaAl}_{4}$-type structure or its ternary variant $\mathrm{CeAl}_{2} \mathrm{Ga}_{2}$ ) and layers of trigonal prisms (fragment of $\mathrm{AlB}_{2}$-type structure),

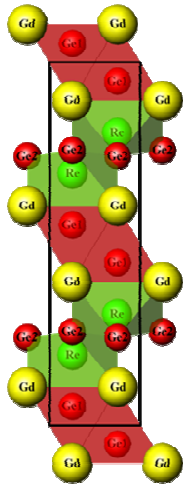

('eNiSi ${ }_{2}(\mathrm{Cmcm})$

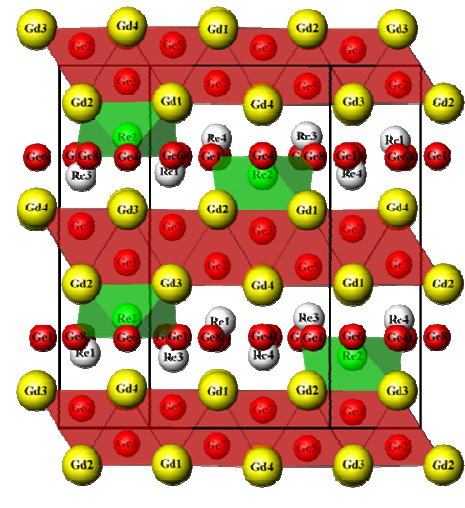

$\operatorname{Gd}_{4} \operatorname{ReGe}_{g}\left(P_{-1} c\right)$
Fig. 2 Comparison of the structure types $\mathrm{CeNiSi}_{2}$ and $\mathrm{Gd}_{4} \mathrm{ReGe}_{8}$. which alternate along the $y$-axis in the ratio $1: 1$. Similar fragments were found in the new structure type $\mathrm{Gd}_{4} \operatorname{ReGe}_{8}$ (Fig. 2). In both structures the square antiprisms and trigonal prisms are connected by common faces, but in the structure of $\mathrm{CeNiSi}_{2}$ two neighboring antiprisms, shifted by $1 / 2$ perpendicular to the $z$-axis, share edges. In the structure of $\mathrm{Gd}_{4} \mathrm{ReGe}_{8}$ neighboring antiprisms with more than $5 \%$ occupation of the central site are separated.

The unit cell of the new structure type can be derived from that of the parent structure $\mathrm{CeNiSi}_{2}$ (see Table 4, blue square on Fig. 3). The partial ordering of $75 \%$ vacancies on the $d$-element site is accompanied by a four-time increase of the cell, and by a decrease in symmetry. The transformation can be described using the Bärnighausen formalism (group-subgroup relations). The first operation considered here is the elimination of the side-centering of the Bravais lattice, which leads to space group Pbnm and releases the constraints on the $x$-coordinates (model II). At the next step the symmetry is decreased to the monoclinic space group $P 2_{1} / n$, which implies release of the constraints on the $z$-coordinates (model III). Standardization to space group setting $P 2_{1} / c$ (model III', red parallelogram on Fig. 3) changes only the cell parameters (the new parameter $a$ is former $c$, and the new parameter $c$ is the diagonal between the old parameters $c$ and $a$ ). Only four of the original symmetry elements remain in this monoclinic structure. The next operation consists in increasing the cell by a factor 2 along the $x$-axis, by that doubling the number of independent atom sites, a first time (model IV, green parallelogram on Fig. 3), and then once more (model V, yellow parallelogram on Fig. 3). At this step, there are 16 atom sites in Wyckoff position $4 e$ : four for $\mathrm{Gd}$ atoms, four for Re atoms and eight for $\mathrm{Ge}$ atoms. The last operation is again a standardization to space group setting $P 2_{1} / c$ (model $\mathrm{V}^{\prime}$, violet parallelogram on Fig. 3). 
Table 4 Transformation from the structure type $\mathrm{CeNiSi}_{2}$ (compound $\mathrm{GdRe}_{0.25} \mathrm{Ge}_{2}$ ) to the structure type $\mathrm{Gd}_{4} \operatorname{ReGe}_{8}$.

\begin{tabular}{|c|c|c|c|c|}
\hline Model & I CeNiSi ${ }_{2}$ & II & III & III' \\
\hline Group-subgroup relation & & IIa & $\mathrm{I}$ & 0 \\
\hline Transformation matrix & & $\begin{array}{lll}1 & 0 & 0 \\
0 & 1 & 0 \\
0 & 0 & 1\end{array}$ & $\begin{array}{lll}1 & 0 & 0 \\
0 & 1 & 0 \\
0 & 0 & 1 \\
\end{array}$ & $\begin{array}{rrl}0 & 0 & 1 \\
0 & 1 & 0 \\
-1 & 0 & -1 \\
\end{array}$ \\
\hline Space group & (63) $\mathrm{Cmcm}$ & (62) Pbnm & (14) $P 2_{1} / n$ & (14) $P 2_{1} / c$ \\
\hline Unit-cell parameters, $\AA$ & $\begin{array}{c}a_{\mathrm{I}}=4.1571 \\
b_{\mathrm{I}}=16.0583 \\
c_{\mathrm{I}}=4.0543\end{array}$ & $\begin{array}{c}a_{\mathrm{II}}=4.1571 \\
b_{\mathrm{II}}=16.0583 \\
c_{\mathrm{II}}=4.0543\end{array}$ & $\begin{array}{c}a_{\mathrm{III}}=4.1571 \\
b_{\mathrm{III}}=16.0583 \\
c_{\mathrm{III}}=4.0543 \\
\beta_{\mathrm{III}}=90.0^{\circ}\end{array}$ & $\begin{array}{c}a_{\mathrm{III}}=4.0543 \\
b_{\mathrm{III}}=16.0583 \\
c_{\mathrm{III}}=5.8068 \\
\beta_{\mathrm{III}}=134.28^{\circ}\end{array}$ \\
\hline $\begin{array}{c}\text { Atom, } \\
\text { Wyckoff position, } \\
\text { coordinates }\end{array}$ & $\begin{array}{l}\mathrm{Gd} 4 c 0,0.3990,1 / 4 \\
\operatorname{Re}^{\mathrm{a}} 4 c 0,0.1980,1 / 4 \\
\mathrm{Ge} 14 c 0,0.0501,1 / 4 \\
\mathrm{Ge} 24 c 0,0.7501,1 / 4\end{array}$ & $\begin{array}{l}\mathrm{Gd} 4 c 0.0,0.3990,1 / 4 \\
\operatorname{Re}^{\mathrm{a}} 4 c 0.0,0.1980,1 / 4 \\
\mathrm{Ge} 14 c 0.0,0.0501,1 / 4 \\
\mathrm{Ge} 24 c 0.0,0.7501,1 / 4\end{array}$ & $\begin{array}{l}\mathrm{Gd} 4 e 0.0,0.3990,0.25 \\
\operatorname{Re}^{\mathrm{a}} 4 e 0.0,0.1980,0.25 \\
\mathrm{Ge} 14 e 0.0,0.0501,0.25 \\
\mathrm{Ge} 24 e 0.0,0.7501,0.25\end{array}$ & $\begin{array}{l}\operatorname{Gd} 4 e 0.25,0.3990,0.0 \\
\operatorname{Re}^{\mathrm{a}} 4 e 0.25,0.1980,0.0 \\
\mathrm{Ge} 14 e 0.25,0.0501,0.0 \\
\mathrm{Ge} 24 e 0.25,0.7501,0.0\end{array}$ \\
\hline Symmetry elements & $\begin{array}{c}1,2,2,2,-1, \\
m, c, m, t, 2, \\
2,2,-1, n, n, b\end{array}$ & $\begin{array}{c}1,2, \frac{2,2}{2}-1, \\
m, 2,2,2, b \\
2,2,1, n, b\end{array}$ & $\begin{array}{l}1,2,2,2,-1, \\
m, 2,2, \\
2,2,1, n, b\end{array}$ & $1,2,-1, c$ \\
\hline
\end{tabular}

\begin{tabular}{|c|c|c|c|}
\hline Model & IV & $\mathbf{V}$ & $V^{\prime} \mathbf{G d}_{4} \operatorname{ReGe}_{8}$ \\
\hline Group-subgroup relation & IIc & III & 0 \\
\hline Transformation matrix & $\begin{array}{rrl}0 & 0 & 2 \\
0 & 1 & 0 \\
-1 & 0 & -1\end{array}$ & $\begin{array}{rrl}0 & 0 & 4 \\
0 & 1 & 0 \\
-1 & 0 & -1\end{array}$ & $\begin{array}{ccc}-1 & 0 & -1 \\
0 & -1 & 0 \\
-1 & 0 & 3\end{array}$ \\
\hline Space group & (14) $P 2_{1} / c$ & (14) $P 2_{1} / n$ & (14) $P 2{ }_{1} / c$ \\
\hline Unit-cell parameters, $\AA$ & $\begin{array}{c}a_{\mathrm{IV}}=8.1086 \\
b_{\mathrm{IV}}=16.0583 \\
c_{\mathrm{IV}}=5.8068 \\
\beta_{\mathrm{IV}}=134.28^{\circ}\end{array}$ & $\begin{array}{c}a_{\mathrm{V}}=16.2172 \\
b_{\mathrm{V}}=16.0583 \\
c_{\mathrm{V}}=5.8068 \\
\beta_{\mathrm{V}}=134.28^{\circ}\end{array}$ & $\begin{array}{c}a_{\mathrm{V}^{\prime}}=5.8068 \\
b_{\mathrm{V}^{\prime}}=16.0583 \\
c_{\mathrm{V}^{\prime}}=12.8537 \\
\beta_{\mathrm{V}^{\prime}}=115.41^{\circ}\end{array}$ \\
\hline $\begin{array}{c}\text { Atom, } \\
\text { Wyckoff position, } \\
\text { coordinates }\end{array}$ & $\begin{array}{l}\text { Gd1 } 4 e 0.125,0.3990,0.0 \\
\text { Gd2 } 4 e 0.625,0.3990,0.0 \\
\operatorname{Re}^{\mathrm{a}} 4 e 0.125,0.1980,0.0 \\
\operatorname{Re}^{\mathrm{a}} 4 e 0.625,0.1980,0.0 \\
\text { Ge1 } 4 e 0.125,0.0501,0.0 \\
\text { Ge2 } 4 e 0.625,0.0501,0.0 \\
\text { Ge3 } 4 e 0.125,0.7501,0.0 \\
\text { Ge4 } 4 e 0.625,0.7501,0.0\end{array}$ & $\begin{array}{l}\mathrm{Gd} 14 e 0.0625,0.3990,0.0 \\
\mathrm{Gd} 24 e 0.5625,0.3990,0.0 \\
\mathrm{Gd} 34 e 0.3125,0.3990,0.0 \\
\mathrm{Gd} 44 e 0.8125,0.3990,0.0 \\
\mathrm{Re}^{\mathrm{a}} 4 e 0.0625,0.1980,0.0 \\
\mathrm{Re}^{\mathrm{a}} 4 e 0.5625,0.1980,0.0 \\
\mathrm{Re}^{\mathrm{a}} 4 e 0.3125,0.1980,0.0 \\
\mathrm{Re}^{\mathrm{a}} 4 e 0.8125,0.1980,0.0 \\
\mathrm{Ge} 14 e 0.0625,0.0501,0.0 \\
\mathrm{Ge} 24 e 0.5625,0.0501,0.0 \\
\mathrm{Ge} 34 e 0.3125,0.0501,0.0 \\
\mathrm{Ge} 44 e 0.8125,0.0501,0.0 \\
\mathrm{Ge} 54 e 0.0625,0.7501,0.0 \\
\mathrm{Ge} 64 e 0.5625,0.7501,0.0 \\
\mathrm{Ge} 74 e 0.3125,0.7501,0.0 \\
\mathrm{Ge} 84 e 0.8125,0.7501,0.0\end{array}$ & $\begin{array}{l}\text { Gd1 } 4 e 0.0625,0.1010,0.4375 \\
\text { Gd2 } 4 e 0.5625,0.3990,0.4375 \\
\text { Gd3 } 4 e 0.3125,0.1010,0.1875 \\
\text { Gd4 } 4 e 0.8125,0.3990,0.1875 \\
\text { Re1 } 4 e 0.0625,0.3020,0.4375 \\
\text { Re2 } 4 e 0.5625,0.1980,0.4375 \\
\text { Re3 } 4 e 0.3125,0.3020,0.1875 \\
\text { Re4 } 4 e 0.8125,0.1980,0.1875 \\
\text { Ge1 } 4 e 0.0625,0.4499,0.4375 \\
\text { Ge2 } 4 e 0.5625,0.0501,0.4375 \\
\text { Ge3 } 4 e 0.3125,0.4499,0.1875 \\
\text { Ge4 } 4 e 0.8125,0.0501,0.1875 \\
\text { Ge5 } 4 e 0.0625,0.7499,0.4375 \\
\text { Ge6 } 4 e 0.5625,0.7501,0.4375 \\
\text { Ge7 } 4 e 0.3125,0.7499,0.1875 \\
\text { Ge8 } 4 e 0.8125,0.7501,0.1875\end{array}$ \\
\hline Symmetry elements & $1,2,-1, c$ & $1,2,-1, n$ & $1,2,-1, c$ \\
\hline
\end{tabular}

\footnotetext{
${ }^{\mathrm{a}}$ Occ. $=0.25$.
} 



Fig. 3 Transformation from the structure type $\mathrm{CeNiSi}$ to the structure type $\mathrm{Gd}_{4} \mathrm{ReGe}_{8}$ (blue cell: $\mathrm{I} \mathrm{CeNiSi}_{2}$, models II and III, red cell: model III', green cell: model IV, yellow cell: model V, violet cell: $\mathrm{V}^{\prime} \mathrm{Gd}_{4} \mathrm{ReGe}_{8}$ ).

Table 5 Comparison of the atomic coordinates of the theoretical and experimental structures of $\mathrm{Gd}_{4} \operatorname{ReGe}_{8}$ (space group $P 2{ }_{1} / c$ ).

\begin{tabular}{c|l|l|l|l|l|l}
\hline Atom & $x_{\text {theor. }}$ & \multicolumn{1}{|c|}{$x_{\text {exp. }}$} & $y_{\text {theor. }}$ & $y_{\text {exp. }}$ & $z_{\text {theor. }}$ & $z_{\text {exp. }}$ \\
\hline Gd1 & 0.0625 & $0.05953(13)$ & 0.1010 & $0.10009(4)$ & 0.4375 & $0.43430(6)$ \\
Gd2 & 0.3125 & $0.31290(13)$ & 0.1010 & $0.10298(4)$ & 0.1875 & $0.18816(6)$ \\
Gd3 & 0.5625 & $0.56641(13)$ & 0.3990 & $0.39883(4)$ & 0.4375 & $0.44145(6)$ \\
Gd4 & 0.8125 & $0.81161(13)$ & 0.3990 & $0.39195(4)$ & 0.1875 & $0.18627(6)$ \\
Re1 & 0.0625 & $0.066(13)$ & 0.3020 & $0.293(4)$ & 0.4375 & $0.428(5)$ \\
Re2 & 0.1875 & $0.18611(11)$ & 0.6980 & $0.69791(3)$ & 0.3125 & $0.31155(5)$ \\
Re3 & 0.3125 & $0.318(3)$ & 0.3020 & $0.3044(10)$ & 0.1875 & $0.1857(14)$ \\
Re4 & 0.5625 & $0.562(3)$ & 0.1980 & $0.2008(9)$ & 0.4375 & $0.4335(13)$ \\
Ge1 & 0.0625 & $0.0434(3)$ & 0.7499 & $0.74867(9)$ & 0.4375 & $0.45261(13)$ \\
Ge2 & 0.0625 & $0.0634(3)$ & 0.4499 & $0.44663(9)$ & 0.4375 & $0.43841(12)$ \\
Ge3 & 0.1875 & $0.1855(3)$ & 0.5501 & $0.54385(9)$ & 0.3125 & $0.31188(12)$ \\
Ge4 & 0.1875 & $0.2299(3)$ & 0.2501 & $0.25174(9)$ & 0.3125 & $0.32864(13)$ \\
Ge5 & 0.3125 & $0.3139(3)$ & 0.4499 & $0.44346(9)$ & 0.1875 & $0.18579(12)$ \\
Ge6 & 0.4375 & $0.3968(3)$ & 0.2501 & $0.25208(9)$ & 0.0625 & $0.04870(13)$ \\
Ge7 & 0.4375 & $0.4393(3)$ & 0.5501 & $0.54946(9)$ & 0.0625 & $0.06523(12)$ \\
Ge8 & 0.6875 & $0.6734(3)$ & 0.2499 & $0.24886(9)$ & 0.3125 & $0.33061(13)$ \\
\hline
\end{tabular}

The atomic coordinates of the theoretical and experimental structures are compared in Table 5. Selected interatomic distances are listed in Table 6.

All of the four $d$-element positions derived from the parent type $\mathrm{CeNiSi}_{2}$ are present in $\mathrm{Gd}_{4} \mathrm{ReGe}_{8}$, even if the occupation of three of them is very low. However, only two positions exist in the related structure type $\mathrm{Tb}_{4} \mathrm{FeGe}_{8}$ [6]. In the case of $\mathrm{Gd}_{4} \mathrm{ReGe}_{8}$, removal of any of the partly occupied $\mathrm{Re}$ sites from the refinement led to significantly worse reliability factors. The coordinates and occupancies of the atom sites in the structures of $\mathrm{Gd}_{4} \mathrm{ReGe}_{8}$ and $\mathrm{Tb}_{4} \mathrm{FeGe}_{8}$ are presented in Table 7.

The coordination polyhedra of the atoms in $\mathrm{Gd}_{4} \mathrm{ReGe}_{8}$ are related to those of the $\mathrm{CeNiSi}_{2}$ type and can be described as follows: $\mathrm{Gd}\left[\mathrm{Ge}_{8}\right]$ square prisms with three or four additional atoms, $\operatorname{Re}\left[\mathrm{Ge}_{4} \mathrm{Gd}_{4}\right]$ square antiprisms with two additional atoms, $\mathrm{Ge}\left[\mathrm{Gd}_{6}\right]$ trigonal prisms with two or three additional atoms, and $\mathrm{Ge}\left[\mathrm{Gd}_{4} \mathrm{Ge}_{4}\right]$ gyrobifastigia (two trigonal prisms, rotated by $90^{\circ}$ with respect to each other and sharing a square face) with one additional atom. 
The crystal structure of the $\mathrm{Gd}_{4} \mathrm{ReGe}_{8}$ compound can also be represented as a packing of Gd-centered polyhedra formed by Ge atoms. The Re atoms occupy square pyramidal voids in the packing (Fig. 4).

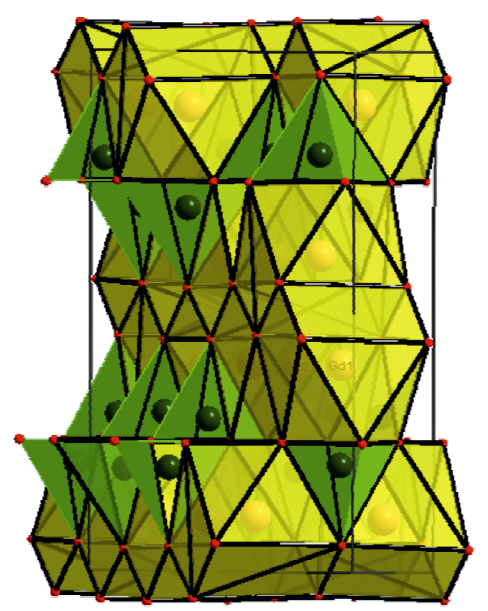

Fig. 4 Packing of Gd-centered polyhedra in the structure of $\mathrm{Gd}_{4} \mathrm{ReGe}_{8}$ (small red circles: $\mathrm{Ge}$ atoms, medium green circles: Re atoms, large yellow circles: Gd atoms).

\section{Conclusions}

The crystal structure of the new ternary germanide $\mathrm{Gd}_{4} \mathrm{ReGe}_{8}$ represents a new structure type (Pearson symbol $m P 64-12$, space group $P 2{ }_{1} / c$ ). Ignoring $\operatorname{Re}$ sites with $<5 \%$ occupation, the coordination polyhedra are square prisms with three or four additional atoms for $\mathrm{Gd}$, square antiprisms with two additional atoms for Re, and trigonal prisms with two or three additional atoms, and gyrobifastigia with one additional atom for Ge. The crystal structure can also be represented as a packing of Gd-centered polyhedra formed by $\mathrm{Ge}$ atoms, with $\mathrm{Re}$ atoms in voids.

The structure of $\mathrm{Gd}_{4} \mathrm{ReGe}_{8}$ can be derived from the $\mathrm{CeNiSi}_{2}$ type by removing $3 / 4$ of the $d$-element atoms and both structure types consequently contain the same basic fragments. Partial ordering of the vacancies causes lowering of the symmetry from orthorhombic to monoclinic and an increase of the cell volume by a factor 4 .

The crystal structure of $\mathrm{Gd}_{4} \mathrm{ReGe}_{8}$ is closely related to the structure type $\mathrm{Tb}_{4} \mathrm{FeGe}_{8}$, where only two of the four $d$-element sites present in $\mathrm{Gd}_{4} \mathrm{ReGe}_{8}$ are occupied.

Table 6 Interatomic distances and coordination numbers in the structure of $\mathrm{Gd}_{4} \mathrm{ReGe}_{8}$. Distances to the sites with $<5 \%$ occupation are ignored.

\begin{tabular}{|c|c|c|c|c|c|c|c|}
\hline \multicolumn{2}{|c|}{ Atoms } & $\delta, \AA$ & $\mathrm{CN}$ & \multicolumn{2}{|c|}{ Atoms } & $\delta, \AA$ & $\mathrm{CN}$ \\
\hline Gd1 & $\begin{array}{l}\text { Ge3 } \\
\text { Ge5 } \\
\text { Ge7 } \\
\text { Ge1 } \\
\text { Ge7 } \\
\text { Ge6 } \\
\text { Ge4 } \\
\text { Ge8 } \\
\text { Ge7 } \\
\text { Ge5 } \\
\text { Re2 }\end{array}$ & $\begin{array}{l}2.999(12) \\
3.004(13) \\
3.013(2) \\
3.019(3) \\
3.021(2) \\
3.028(8) \\
3.148(4) \\
3.155(8) \\
3.207(10) \\
3.248(9) \\
3.259(11)\end{array}$ & 11 & $\mathrm{Gd} 2$ & $\begin{array}{l}\text { Ge7 } \\
\text { Ge2 } \\
\text { Ge3 } \\
\text { Ge3 } \\
\text { Ge1 } \\
\text { Ge6 } \\
\text { Ge8 } \\
\text { Ge4 } \\
\text { Ge2 } \\
\text { Re2 } \\
\text { Re2 } \\
\text { Ge5 }\end{array}$ & $\begin{array}{l}2.991(13) \\
3.008(13) \\
3.048(2) \\
3.066(2) \\
3.134(10) \\
3.152(3) \\
3.153(10) \\
3.154(3) \\
3.269(9) \\
3.277(1) \\
3.285(1) \\
3.298(9)\end{array}$ & 12 \\
\hline $\mathrm{Gd} 3$ & $\begin{array}{l}\text { Ge8 } \\
\text { Ge2 } \\
\text { Ge2 } \\
\text { Ge3 } \\
\text { Ge4 } \\
\text { Ge5 } \\
\text { Ge6 } \\
\text { Ge3 } \\
\text { Ge1 } \\
\text { Ge2 } \\
\text { Re2 }\end{array}$ & $\begin{array}{l}2.996(3) \\
3.004(2) \\
3.006(2) \\
3.010(12) \\
3.013(8) \\
3.055(13) \\
3.148(4) \\
3.152(10) \\
3.156(8) \\
3.213(9) \\
3.263(11) \\
\end{array}$ & 11 & Gd4 & $\begin{array}{l}\text { Ge5 } \\
\text { Ge5 } \\
\text { Ge2 } \\
\text { Ge7 } \\
\text { Re2 } \\
\text { Ge3 } \\
\text { Ge6 } \\
\text { Ge1 } \\
\text { Ge4 } \\
\text { Ge7 } \\
\text { Ge8 }\end{array}$ & $\begin{array}{l}3.005(2) \\
3.036(2) \\
3.058(13) \\
3.069(13) \\
3.116(1) \\
3.205(9) \\
3.214(11) \\
3.237(4) \\
3.242(11) \\
3.258(9) \\
3.263(4) \\
\end{array}$ & 11 \\
\hline
\end{tabular}


Table 6 (continued)

\begin{tabular}{|c|c|c|c|c|c|c|c|}
\hline \multicolumn{2}{|c|}{ Atoms } & \multirow[b]{2}{*}{\begin{tabular}{l}
\multicolumn{1}{c}{$\delta, \AA$} \\
$2.435(5)$ \\
$2.551(3)$ \\
$2.558(15)$ \\
$3.019(3)$ \\
$3.134(10)$ \\
$3.156(8)$ \\
$3.237(4)$ \\
$3.261(3)$ \\
$3.266(2)$
\end{tabular}} & \multirow[b]{2}{*}{$\begin{array}{c}\mathrm{CN} \\
\\
\\
9\end{array}$} & \multicolumn{2}{|c|}{ Atoms } & \multirow[b]{2}{*}{\begin{tabular}{l}
\multicolumn{1}{c}{$\delta, \AA$} \\
$2.564(4)$ \\
$2.643(4)$ \\
$3.004(2)$ \\
$3.006(2)$ \\
$3.008(13)$ \\
$3.058(13)$ \\
$3.213(9)$ \\
$3.269(9)$
\end{tabular}} & \multirow[b]{2}{*}{$\begin{array}{c}\mathrm{CN} \\
\\
\\
8\end{array}$} \\
\hline Ge1 & $\begin{array}{l}\text { Re2 } \\
\text { Ge6 } \\
\text { Ge8 } \\
\text { Gd1 } \\
\text { Gd2 } \\
\text { Gd3 } \\
\text { Gd4 } \\
\text { Ge6 } \\
\text { Ge4 } \\
\end{array}$ & & & $\mathrm{Ge} 2$ & $\begin{array}{l}\mathrm{Ge} 3 \\
\mathrm{Ge} 2 \\
\mathrm{Gd} 3 \\
\mathrm{Gd} 3 \\
\mathrm{Gd} 2 \\
\mathrm{Gd} 4 \\
\mathrm{Gd} 3 \\
\mathrm{Gd} 2\end{array}$ & & \\
\hline Ge3 & $\begin{array}{l}\mathrm{Re} 2 \\
\mathrm{Ge} 2 \\
\mathrm{Ge} 5 \\
\mathrm{Gd} 1 \\
\mathrm{Gd} 3 \\
\mathrm{Gd} 2 \\
\mathrm{Gd} 2 \\
\mathrm{Gd} 3 \\
\mathrm{Gd} 4\end{array}$ & $\begin{array}{l}2.474(2) \\
2.564(4) \\
2.611(5) \\
2.999(12) \\
3.010(12) \\
3.048(2) \\
3.066(2) \\
3.152(10) \\
3.205(9)\end{array}$ & 9 & Ge4 & $\begin{array}{l}\text { Re2 } \\
\text { Ge6 } \\
\text { Ge8 } \\
\text { Gd3 } \\
\text { Gd1 } \\
\text { Gd2 } \\
\text { Gd4 } \\
\text { Ge8 } \\
\text { Ge1 }\end{array}$ & $\begin{array}{l}2.471(14) \\
2.567(9) \\
2.567(3) \\
3.013(8) \\
3.148(4) \\
3.154(3) \\
3.242(11) \\
3.245(3) \\
3.266(2)\end{array}$ & 9 \\
\hline Ge5 & $\begin{array}{l}\text { Ge7 } \\
\text { Ge3 } \\
\text { Gd1 } \\
\text { Gd4 } \\
\text { Gd4 } \\
\text { Gd3 } \\
\text { Gd1 } \\
\text { Gd2 }\end{array}$ & $\begin{array}{l}2.607(4) \\
2.611(5) \\
3.004(13) \\
3.005(2) \\
3.036(2) \\
3.055(13) \\
3.248(9) \\
3.298(9)\end{array}$ & 8 & Ge6 & $\begin{array}{l}\text { Re2 } \\
\text { Ge1 } \\
\text { Ge4 } \\
\text { Gd1 } \\
\text { Gd3 } \\
\text { Gd2 } \\
\text { Gd4 } \\
\text { Ge1 } \\
\text { Ge8 } \\
\end{array}$ & $\begin{array}{l}2.475(14) \\
2.551(3) \\
2.567(9) \\
3.028(8) \\
3.148(4) \\
3.152(3) \\
3.214(11) \\
3.261(3) \\
3.274(2) \\
\end{array}$ & 9 \\
\hline $\mathrm{Ge} 7$ & $\begin{array}{l}\text { Ge5 } \\
\text { Ge7 } \\
\text { Gd2 } \\
\text { Gd1 } \\
\text { Gd1 } \\
\text { Gd4 } \\
\text { Gd1 } \\
\text { Gd4 }\end{array}$ & $\begin{array}{l}2.607(4) \\
2.617(4) \\
2.991(13) \\
3.013(2) \\
3.021(2) \\
3.069(13) \\
3.207(10) \\
3.258(9)\end{array}$ & 8 & Ge8 & $\begin{array}{l}\text { Re2 } \\
\text { Ge1 } \\
\text { Ge4 } \\
\text { Gd3 } \\
\text { Gd2 } \\
\text { Gd1 } \\
\text { Ge4 } \\
\text { Gd4 } \\
\text { Ge6 }\end{array}$ & $\begin{array}{l}2.440(5) \\
2.558(15) \\
2.567(3) \\
2.996(3) \\
3.153(10) \\
3.155(8) \\
3.245(3) \\
3.263(4) \\
3.274(2)\end{array}$ & 9 \\
\hline $\operatorname{Re} 2$ & $\begin{array}{l}\text { Ge1 } \\
\text { Ge8 } \\
\text { Ge4 } \\
\text { Ge3 } \\
\text { Ge6 } \\
\text { Gd4 } \\
\text { Gd1 } \\
\text { Gd3 } \\
\text { Gd2 } \\
\text { Gd2 } \\
\end{array}$ & $\begin{array}{l}2.435(5) \\
2.440(5) \\
2.471(14) \\
2.474(2) \\
2.475(14) \\
3.116(1) \\
3.259(11) \\
3.263(11) \\
3.277(1) \\
3.285(1) \\
\end{array}$ & 10 & & & & \\
\hline
\end{tabular}

Table 7 Positional coordinates and occupancies of the atom sites in the structures of $\mathrm{Gd}_{4} \mathrm{ReGe}_{8}$ (this work) and $\mathrm{Tb}_{4} \mathrm{FeGe}_{8}[6]$ (space group $P 2_{1} / c$, all atoms in Wyckoff position $4 e$ ).

\begin{tabular}{|c|c|c|c|c|c|c|c|c|c|}
\hline \multicolumn{5}{|c|}{$\mathrm{Gd}_{4} \mathrm{ReGe}_{8}$} & \multicolumn{5}{|c|}{$\mathrm{Tb}_{4} \mathrm{FeGe}_{8}$} \\
\hline Atom & $x$ & $y$ & $z$ & Occ. & Atom & $x$ & $y$ & $z$ & Occ. \\
\hline Re1 & $0.066(13)$ & $0.293(4)$ & $0.428(5)$ & $0.008(2)$ & \multicolumn{5}{|c|}{-} \\
\hline $\operatorname{Re} 2$ & $0.18611(11)$ & $0.69791(3)$ & $0.31155(5)$ & $0.916(4)$ & $\mathrm{Fe} 1$ & 0.1881 & 0.6977 & 0.3128 & 0.8 \\
\hline $\operatorname{Re} 3$ & $0.318(3)$ & $0.3044(10)$ & $0.1857(14)$ & $0.0322(16)$ & \multicolumn{5}{|c|}{-} \\
\hline Re4 & $0.562(3)$ & $0.2008(9)$ & $0.4335(13)$ & $0.0345(16)$ & $\mathrm{Fe} 2$ & 0.5662 & 0.1971 & 0.4392 & 0.2 \\
\hline
\end{tabular}




\section{Acknowledgement}

This work was carried out under the grant of the Ministry of Education and Science of Ukraine No. 0115 U003257.

\section{References}

[1] O.I. Bodak, E.I. Gladyshevskii, Kristallografiya 14 (1969) 990.

[2] P. Villars, K. Cenzual (Eds.), Pearson's Crystal Data. Crystal Structure Database for Inorganic Compounds, Release 2013/14, ASM International, Materials Park (OH), 2013.

[3] M. Meyer, G. Venturini, B. Malaman, J. Steinmetz, B. Roques, Mater. Res. Bull. 18 (1983) 1529.

[4] M. François, G. Venturini, E. McRae, B. Malaman, B. Roques, J. Less-Common Met. 128 (1987) 249.

[5] O.I. Bodak, Y.D. Seropegin, O.L. Sologub, V.K. Pecharskii, A.V. Gribanov, Coll. Abstr. $12^{\text {th }}$ Eur. Crystallogr. Meet., Moscow, 1989, p. 2.

[6] M.A. Zhuravleva, D. Bilc, R.J. Pcionek, S.D. Mahanti, M.G. Kanatzidis, Inorg. Chem. 44 (2005) 2177.
[7] H. Schachner, H. Nowotny, H. Kudielka, Monatsh. Chem. 85 (1954) 1140.

[8] G. Venturini, I. Ijjaali, B. Malaman, J. Alloys Compd. 288 (1999) 183.

[9] Y.P. Yarmolyuk, M. Sikiritsa, L.G. Akselrud, L.A. Lysenko, E.I. Gladyshevskii, Sov. Phys. Crystallogr. 27 (1982) 652.

[10] G.M. Sheldrick, Acta Crystallogr. A 64 (2008) 112.

[11] L.J. Farrugia, J. Appl. Crystallogr. 45 (2012) 849.

[12] M. François, G. Venturini, B. Malaman, B. Roques, J. Less-Common Met. 160 (1990) 197.

[13] V. Fedyna, R. Gladyshevskii, Coll Abstr. XII Int. Conf. Cryst. Chem. Intermet. Compd, Lviv, 2013, p. 137.

[14] R. Gladyshevskii, B. Belan, P. Demchenko, V. Fedyna, Yu. Lutsyshyn, Coll. Abstr. $19^{\text {th }}$ Int. Conf. Solid Compd. Transition Elem. (SCTE 2014), Genova, 2014, p. 98.

[15] V. Fedyna, R. Kozak, R. Serkiz, R. Gladyshevskii, Coll. Abstr. XIX Ukr. Conf. Inorg. Chem., Odesa, 2014, p. 237. 